Brit. J. industr. Med., 1960, 17, 167.

\title{
DECOMPRESSION SICKNESS DURING CONSTRUCTION OF THE DARTFORD TUNNEL
}

\author{
BY
}

\author{
F. CAMPBELL GOLDING ${ }^{1}$, P. GRIFFITHS ${ }^{2}$, H. V. HEMPLEMAN ${ }^{3}$, W. D. M. PATON ${ }^{4}$, \\ and D. N. WALDER ${ }^{5}$ \\ A Report by the Dartford Decompression Sickness Panel of the Medical Research Council.
}

(RECEIVED FOR PUBLICATION MARCH 2, 1960)

A clinical, radiological and statistical survey has been made of decompression sickness during the construction of the Dartford Tunnel. Over a period of two years, 1,200 men were employed on eight-hour shifts at pressures up to 28 pounds per square inch (p.s.i.). There were 689 cases of decompression sickness out of 122,000 compressions, an incidence of $0.56 \%$.

The majority of cases $(94.9 \%)$ were simple "bends". The remainder $(5.1 \%)$ exhibited signs and symptoms other than pain and were more serious. All cases were successfully treated and no fatality or permanent disability occurred. In two serious cases, cysts in the lungs were discovered. It is suggested that these gave rise to air embolism when the subjects were decompressed, and pulmonary changes may contribute more than hitherto believed to the pathogenesis of bends. Some other clinical features are described, including "skin-mottling" and an association between bends and the site of an injury. The bends rate is higher for the back shift ( 3 p.m. to 11 p.m.) and the night shift (11 p.m. to 7 a.m.) than for the day shift. In the treatment of decompression sickness it appears to be more satisfactory to use the minimum pressure required for relief of symptoms followed by slow decompression with occasional "soaks", than to attempt to drive the causative bubbles into solution with high pressures.

During the contract the decompression tables recently prescribed by the Ministry of Labour were used. Evidence was obtained that they could be made safer, and that the two main assumptions on which they are based (that sickness will not occur at pressures below 18 p.s.i., and that a man saturates in four hours) may be incorrect. It is desirable to test tables based on 15 p.s.i. and eighthour saturation. The existence of acclimatization to pressure was confirmed; it is such that the bends rate may fall in two to three weeks to $0.1 \%$ of the incidence on the first day of exposure. Acclimatization is lost again, with a "half-time" of about seven days, if a man is away from work.

A study of bone damage in compressed air work has been started. In certain radiographs, abnormalities have been seen which may represent an early stage of caisson disease of bone.

The new tunnel between Kent and Essex under the Thames at Dartford is part of a four miles road link between A2, the London-Rochester road, and A13, the Barking-Southend road. It is situated 14 miles down river from the Blackwall Tunnel, until now the most easterly point at which it has been possible to cross the Thames by road. The river at Dartford is half a mile wide, so that the total length of the tunnel, including the sloping approaches at each end, will be approximately one mile. The

\footnotetext{
Address: ${ }^{1}$ X-ray Department, Middlesex Hospital.

2 Royston, Bayleys Hill, Sevenoaks, Kent.

3 R.N. Physiological Laboratory, Alverstoke.

- Department of Pharmacology, Oxford.

${ }_{5}$ University Department of Surgery, Newcastle on Tyne.
}

tunnel lies about $20 \mathrm{ft}$. below the existing bed of the river in strata which consist of soft blue peaty clay overlying gravel which in turn overlies solid chalk. The preliminary pilot tunnel was completed in 1938, and the present contract for the full tunnel was let in 1956. It has an internal diameter of $28 \mathrm{ft} .2$ in. and will accommodate two $10 \mathrm{ft}$. 6 in. traffic lanes with $16 \mathrm{ft}$. headroom, and be able to take double decker buses.

When constructing such tunnels, situated only a short distance underneath the river bed, it is necessary to use compressed air within the workings in order to keep out the water which would otherwise percolate through the surrounding strata and flood the tunnel. The pressure required to keep the tunnel 
dry varies according to the type of strata through which the tunnel is passing, and also with the depth of the river which at this point is tidal. In this project compressed air at pressures up to 28 pounds per square inch (p.s.i.) has been necessary.

The use of compressed air results in exposing the men who build the tunnel to the risk of decompression sickness. The risk can be minimized by taking certain precautions which have been laid down by the Minister of Labour and National Service in the Work in Compressed Air Special Regulations, 1958.

In spite of adherence to the prescribed precautions, however, a number of cases of decompression sickness still occur, and it is because of this that the present investigation has been carried out.

\section{Arrangement of Workings}

First two vertical shafts were sunk, one on each bank of the river, $2,832 \mathrm{ft}$. apart. From both of these, tunnelling was then begun towards the centre of the river.

A few months before these under-river tunnels from the two sides met, tunnelling under compressed air was started in a landward direction from the bottom of the Kent shafts, working towards the surface portal; about $200 \mathrm{ft}$. had been completed at the time of the junction.

All this work has had to be carried out in compressed air, which was first used on the Kent side in April 1957, and on the Essex side in September 1957. Owing to the slightly different nature of the ground on the two sides, pressures up to 28 p.s.i. have been used on the Kent side, but only up to 21 p.s.i. on the Essex side.

About six months before the tunnel across the river was completed, the pressure on the two sides was equalized.

Decompression Air Locks.-In order to get men and materials in and out of the tunnel whilst maintaining the pressure within, it was necessary to build air locks at both entrances to the workings. These air locks were situated at the bottom of the shafts in a short access tunnel; on each side of the river there was a man lock $12 \mathrm{ft}$. diameter by $33 \mathrm{ft}$. long (this was fitted with benches and could hold 50 men), and a material lock $7 \mathrm{ft}$. diameter by $28 \mathrm{ft}$. long. Heaters (two of $5 \mathrm{Kw}$. capacity) were fitted in the man lock to minimize discomfort when the temperature suddenly fell during the rapid phase of decompression. The locks were at all times controlled by a trained lock keeper, who was also responsible for keeping records of all persons entering and leaving the tunnel and ensuring that they received the correct decompression.
Medical Air Locks.-On each side of the river, situated at the medical centres, each within 100 yards of the top of the shafts, were two medical recompression chambers (each $7 \mathrm{ft}$. diameter and $14 \mathrm{ft}$. long). They were fully equipped with air lock entrances so that the doctor in charge and medical attendants could enter and leave during a recompression if it was necessary to examine or treat the patient, and so that food, books and other things could be passed in and out without interfering with the recompression.

Population at Risk and Working Shifts.-Over a period of two years (April, 1957 to April, 1959) 1,200 men have worked in compressed air on this contract, with between 250 and 320 on the active list at any one time. This has involved 122,000 compressions, of which 119,000 were at pressures over 16 p.s.i. Of the men, 1,060 were shift workers and 140 non-shift workers.

Throughout the duration of the compressed air work, a shift system has been in operation. Three shifts of approximately 25-30 men per shift are worked during the 24 hours, the men spending eight hours in the compressed air, followed by whatever period of time is necessary in the man lock to ensure proper decompression under the prevailing circumstances. In addition to the shift workers, there was a group of men (engineers, electricians, carpenters, fitters) entering and leaving the tunnel to perform tasks, the duration of which did not coincide with that of the regular shifts, who also had to be decompressed according to their exposure to compressed air.

\section{Clinical Data}

Definition.-It is first necessary to define what, for the purposes of this paper, should be regarded as decompression sickness. Many men suffer minor pains ("niggles") after decompression but these are too indefinite for quantitative study. Therefore only those cases with symptoms sufficiently severe to bring the man back for treatment have been counted as decompression sickness, and they were, in fact, always recompressed.

Classification of Cases.-There were 685 cases of decompression sickness. It was found that they could be divided into two types: Type 1, or simple "bends", which accounted for 650 of the total and Type 2, more serious and more complicated, of which there were 35 .

TYPE 1 CASES.-In these the complaint was one of pain, usually described as being in or around a joint. In $85 \%$ the lower limbs only were affected; in $7 \%$, upper limbs only; in $8 \%$ both upper and 
lower limbs. The pain varied in intensity from a "nagging ache" to a very severe pain. It started on the average about three hours after decompression, but the time of onset varied considerably, from immediately after decompression to 12 hours later. Ninety-two per cent of the cases had worked shifts of eight hours or longer; $3 \%$ had worked for four hours only.

About half the cases responded quickly to recompression, but the remainder needed to be kept above working pressure for periods up to one hour before relief of pain was obtained. The most difficult case was that of a miner (Case 499) who had to be recompressed 10 times in all before he obtained complete relief of pains in the shoulders. On 12 occasions men suffering from the bends went back to work in the tunnel, without first reporting for medical recompression, and were not relieved of their symptoms; they had to be brought out from the tunnel and recompressed to a higher pressure in the medical lock in order to get relief.

Sometimes there was a history of bruising, sprain, or excessive use of the part of the body in which the bends pain arose. In 29 cases out of $502(6 \%)$, over a period of 19 months, the evidence was sufficiently definite to be entered on the case sheet. In one case (Case 288) a man bruised his head in the tunnel, causing a small haematoma. Ten hours after decompression he returned from his home to the medical centre (a journey of 25 miles) with acute pain in the haematoma; on recompression the pain went at 10 p.s.i. and did not return. Among fitters, who frequently work in cramped or kneeling positions, the bends incidence was approximately $50 \%$ higher than among other workers. After a mild electric shock, one man (Case 348) suffered bends in the affected arm and shoulder. Some workers attributed their attacks to such causes as tiredness, lack of sleep or change of occupation in the tunnel involving the excessive use of muscles not "in training". Age does not seem to be important: as an example, two men who gave the wrong age and were found to be over $\mathbf{5 0}$ worked two years as labourers without trouble. The average age of Type 1 cases was 30 years.

Type 2 CASEs.-These have been defined as patients presenting with symptoms other than pain or with abnormal physical signs. A summary of the presenting signs and symptoms in these cases is as follows: 26 with vertigo, 15 with signs of "shock" (pale, clammy, thready pulse, hypotension), six with visual symptoms, five with paralysis of limbs, five with epigastric pain, four with dyspnoea, three with speech defects, one with epileptiform attack, one with signs suggesting a cardiac lesion and one who collapsed and was unconscious on leaving the decompression lock. In addition to these 35 cases some men volunteered information about symptoms for which they had not requested treatment: 10 men reported brief attacks of "shortness of breath" on the way home, and two had visual symptoms within two hours of decompression.

The Type 2 cases always start early: six cases started either during the final stages of decompression or at its end; 26 cases started within one hour of the end of decompression. One case occurred six hours after decompression. The average time of onset was approximately $50 \mathrm{~min}$. after decompression. The average age of the Type 2 cases was 36 years, somewhat higher than that of Type 1 cases.

No obvious predisposing cause was found; long exposure to pressure was not essential, for 11 cases had been exposed for five hours or less. In no case was the attack due to faulty decompression.

In general these cases reacted to therapeutic recompression more dramatically than did Type 1 cases; improvement usually began at comparatively low pressures, often considerably below working pressure (Table 1).

TABLE 1

COMPARISON OF SALIENT FEATURES OF TYPE 1 AND TYPE 2 CASES

\begin{tabular}{|c|c|c|}
\hline & Type 1 & Type 2 \\
\hline Symptoms & Limb or joint pain & Diverse \\
\hline Latency of onset & $\begin{array}{l}\text { 0-12 hours from end } \\
\text { of decompression } \\
\text { Mean three hours }\end{array}$ & $\begin{array}{l}\text { Before end of decom- } \\
\text { pression to six hours } \\
\text { after } 50 \text { minutes } \\
\text { Mean }\end{array}$ \\
\hline $\begin{array}{l}\text { Response to decom- } \\
\text { pression }\end{array}$ & $\begin{array}{l}\text { Good but some- } \\
\text { times slow }\end{array}$ & $\begin{array}{l}\text { Dramatic, sometime } \\
\text { at quite low pressure }\end{array}$ \\
\hline Age & Mean 30 years & Mean 36 years \\
\hline Predisposing factors & $\begin{array}{l}\text { Injury, fatigue, ische- } \\
\text { mia, long exposure }\end{array}$ & $\begin{array}{l}\text { Lung cyst } \\
\text { Long exposure not } \\
\text { necessary }\end{array}$ \\
\hline No. of cases & 650 & 35 \\
\hline
\end{tabular}

The following case histories illustrate some of the features mentioned:

\section{Case Histories}

Case 23.- This man, after working for eight hours at 21 p.s.i. fainted in the man lock during decompression with his shift, but recovered immediately. He was kept under observation for two hours and then allowed to go home apparently fit. Paralysis of legs and bladder came on gradually during the night, and it was 12 hours after decompression before treatment began. Relief of symptoms by recompression was successful, although a pressure much higher than working pressure was needed. Great difficulty was experienced in returning this patient to atmospheric pressure; despite the use of very slow decompression with periods of prolonged equilibration 


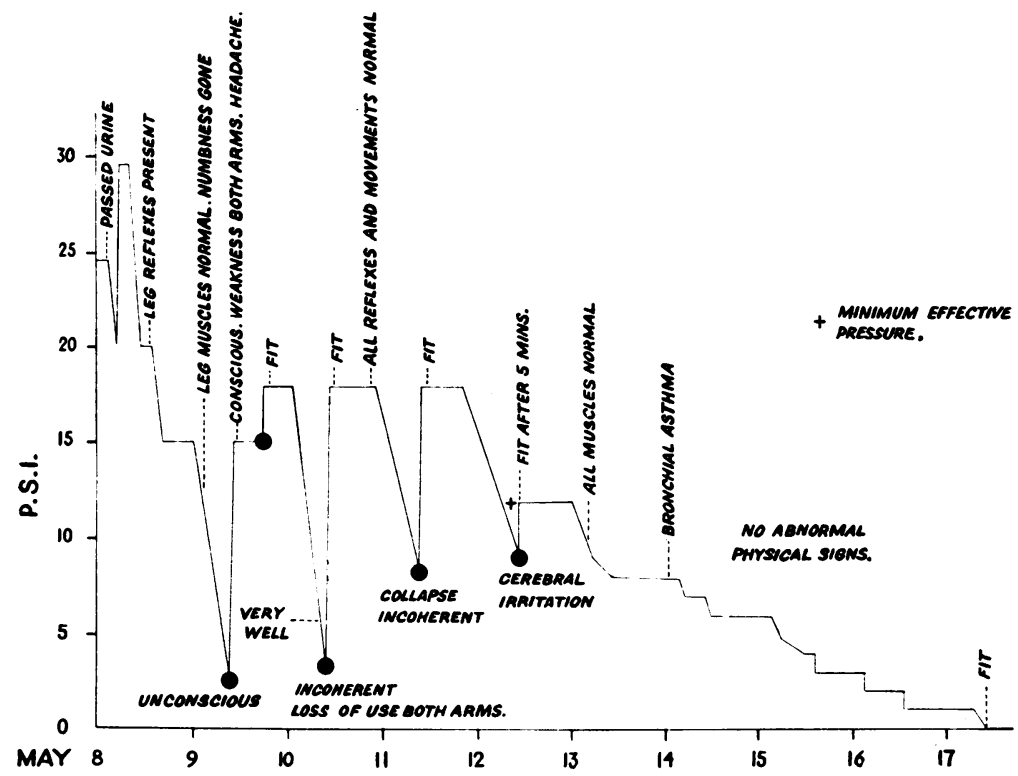

Fig. 1.-Diagram of the therapeutic recompression of Case 23, presenting with retention of urine and loss of reflexes in both legs, after an eight-hour shift at 21 p.s.i. The filled circles denote the pressure at which symptoms or signs recurred. (In medical lock 91 days.)

at intermediate pressures (the so-called "soaks") and of oxygen inhalation, it was nine and a half days before he could be released from pressure without a return of symptoms. Fig. 1 shows his treatment diagrammatically. Especially remarkable was the manner in which paralysis of the lower or upper limbs returned within $2 \mathrm{lb}$. of atmospheric pressure in spite of lowering the pressure at a rate of only $1 \frac{1}{2} \mathrm{lb}$. per hour, and later recurred with a rate three times slower. The only physical abnormality detected at subsequent medical examination was the cyst at the base of the right lung mentioned elsewhere in this paper.

Case 268.-An engineer aged 55 fell unconscious on leaving the man lock, after only three-quarters of an hour at 26 p.s.i. He was recompressed immediately in the man lock and kept at 26 p.s.i. When he recovered consciousness 20 minutes later he could move neither arms nor legs; all reflexes were exaggerated and plantar responses extensor. Thirty minutes later he was free of symptoms and had normal reflexes. He was very slowly decompressed and quickly transferred to the medical lock where further recompression and decompression treatment was completed. Both ear drums were damaged during the initial emergency recompression, but they healed quickly without disability. Subsequent investigation showed him to be a fit man, but radiological investigation of his chest revealed a cyst at the base of the right lung.

Case 341.-An engineer aged 48 collapsed with signs of "shock" 15 minutes after an exposure of one hour at 26 p.s.i. He recovered quickly on recompression and no other ill effects were detected. Later, a radiograph of his chest (AP) appeared normal.

Both these engineers had been exposed repeatedly to compressed air for many years without previous trouble.
Case 9.-A chargehand fitter aged 41 had "staggers", and was apparently cured by treatment in the medical lock. One hour later, while still under observation, he collapsed unconscious, with a pulse rate of 40 . Within five minutes of recompression he was conscious and well, with a pulse rate of 78 , and no further trouble was experienced. With this man, also, an AP chest radiograph was normal.

Skin Mottling.-An interesting sign seen in some subjects after decompression is the occurrence of a purplish patchy discolouration of the skin, known as "mottling" (Fig. 2). This disappears on local pressure, returning when pressure is released. The area most commonly affected was the upper abdomen but occasionally it was seen spreading to the back and down the limbs.

Faint mottling was often seen over the upper abdomen during routine inspection, but unless associated with symptoms, was ignored. Some authorities consider the occurrence of skin mottling to be an indication of grave prognostic significance; and therefore any man with severe mottling, with or without other symptoms, was either forbidden to work in compressed air, or limited as to time and pressure.

Twenty-two men showed extensive mottling and of these, 15 were obese. In 15 cases, there were other symptoms requiring recompression; in seven cases, the men reported the mottling but had no symptoms other than skin irritation. One fitter (Case 126) who used a hammer for four hours at 24 p.s.i. within an hour of decompression had a 


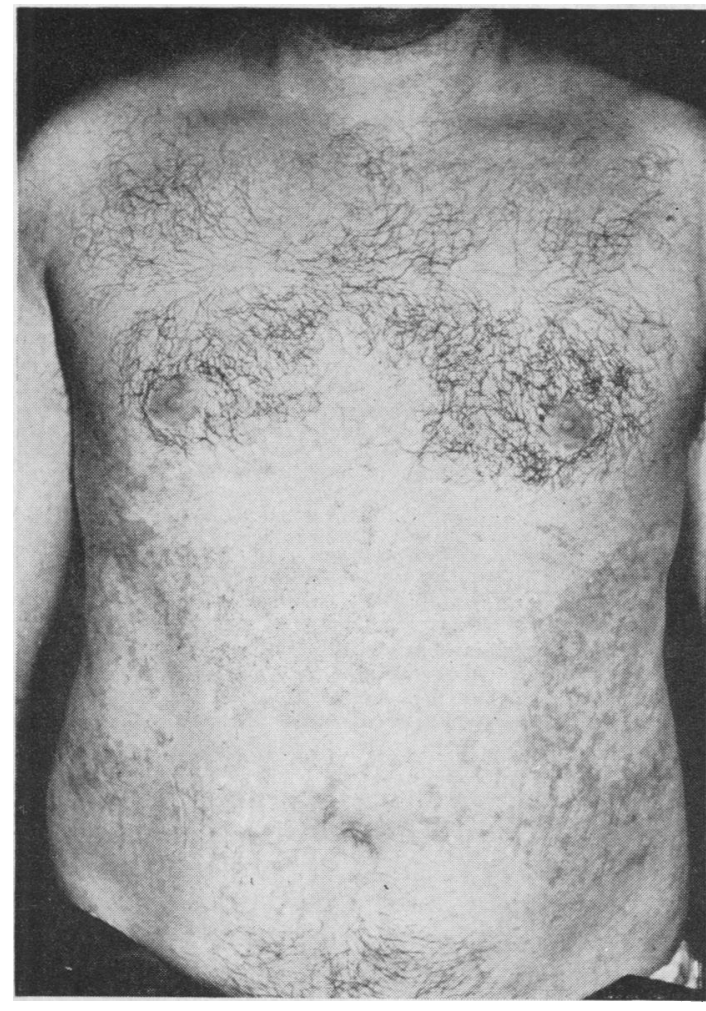

Fig. 2.-Photograph of mottling of the trunk after normal decompression of a shift worker from a pressure of 26 p.s.i.

symptomless deep purple discolouration over the right shoulder and chest, covering almost exactly the muscles most used in hammering.

Cases Occurring among Men exposed to Pressures Less than 18 p.s.i. - Since bends are usually supposed to be rare at pressures less than 18 p.s.i., some details of those occurring at Dartford require mention. There were 45 cases, 41 being Type 1 , and the remaining four Type 2 . Table 2 shows the pressures at which they occurred. Of the Type 1 series, one man had worked only four hours; three others had worked 10 hours or more. The Type 2 cases had all worked eight-hour shifts.

TABLE 2

CASES OF DECOMPRESSION SICKNESS AT PRESSURES LESS THAN 18 p.s.i.

\begin{tabular}{c|c|c}
\hline Pressure (p.s.i.) & Type 1 Cases & Type 2 Cases \\
\hline 16 & $\overline{6}$ & $\frac{1}{1}$ \\
$16 \frac{1}{2}$ & 23 & $\frac{1}{2}$ \\
$17 \frac{1}{2}$ & 12 & \\
\hline
\end{tabular}

The occurrence of cases, both non-serious and serious, at these low pressures, raised the question of the accuracy of the pressure gauges. All pressures were recorded on three separate large scale gauges which were calibrated regularly by the makers, Messrs. Elliott Bros. At no time were errors more than 0.5 p.s.i. detected and they were always such that the recorded pressure was higher than the true pressure.

\section{Radiological Studies}

The construction of a tunnel under the Thames at Dartford presented an opportunity to carry out a radiological survey on men working in compressed air. This was made possible by the loan of radiographic apparatus from the Royal Air Force and facilitated by the cooperation of the contractors. The apparatus was installed in the medical centre, close to the shaft when the tunnel was about half-way to completion. The original intention was to radiograph the limbs of those men who had suffered an attack of bends, in order to determine the incidence of aseptic necrosis in bone, but this objective was later extended to include some workers who had escaped a frank attack of bends but had had minor symptoms described as niggles, or had suffered from mottling of the skin. Coincident with this survey, two examples of severe decompression sickness were encountered. A radiograph of the chest showed that both men had lung cysts. At this time no relationship had been established, either by other investigators or by ourselves, between disease of the lungs and these major attacks, but after these events a radiograph of the chest was taken of all men starting to work in compressed air.

Bone and Joint Lesions. - The literature contains many examples of bone and joint lesions attributed to decompression sickness. Nearly all these were patients who attended hospital because they complained of symptoms. The extent to which bone changes occur without symptoms has hardly been explored. The lesions in bones and joints consist of sclerotic changes in the medulla which often terminate as "lakes" in the bone, and a varying degree of destruction of articular surfaces, the predominant feature being sclerosis. The radiology of aseptic necrosis has been described many times and does not require review here.

Radiographs were taken of the shoulders, hip joints and knee joints, including a large part of the diaphysis, in each case. In the early part of the survey only experienced compressed-air workers were examined, men who had had one or more attacks of bends. There were 83 men in this group and none of them complained of symptoms. 
TABLE 3

BONE SCLEROSIS IN COMPRESSED AIR WORKERS

\begin{tabular}{|c|c|c|c|c|}
\hline Age & $\begin{array}{c}\text { Period of Employment } \\
\text { in Compressed Air } \\
\text { (years) }\end{array}$ & $\begin{array}{c}\text { Maximum Pressure } \\
\text { Worked } \\
\text { (p.s.i.) }\end{array}$ & $\begin{array}{c}\text { Number of Attacks } \\
\text { of Bends } \\
\text { Experienced }\end{array}$ & Radiological Findings: Sites of Sclerosis \\
\hline $\begin{array}{l}43 \\
61\end{array}$ & $\begin{array}{l}22 \\
31\end{array}$ & $\begin{array}{l}40 \\
40\end{array}$ & $\underset{6}{\text { Many }}$ & \multirow{6}{*}{$\begin{array}{l}\text { Right shoulder upper shaft } \\
\text { Femora lower shaft } \\
\text { Tibiae upper shaft probably } \\
\text { Femora lower shaft } \\
\text { Tibiae upper shaft probably } \\
\text { Right humerus at joint } \\
\text { Right femur-joint at hip } \\
\text { Left femur lower shaft probably } \\
\text { Right femur lower shaft } \\
\text { Left femur doubtful lower shaft } \\
\text { Femora lower shaft } \\
\text { Left humerus at joint } \\
\text { Right humerus probably at joint } \\
\text { Femur upper shaft } \\
\text { Right humerus upper shaft } \\
\text { Left humerus joint } \\
\text { Right femur upper shaft } \\
\text { Right femur-joint at hip } \\
\text { Femora lower shaft } \\
\text { Left femur-joint at hip } \\
\text { Left femur at hip joint }\end{array}$} \\
\hline 40 & 12 & 40 & $\begin{array}{l}3 \text { attacks of staggers } \\
\text { and chokes }\end{array}$ & \\
\hline 40 & 10 & 46 & 6 & \\
\hline 34 & 5 & 42 & 1 & \\
\hline 43 & 8 & $1^{40}$ & 7 & \\
\hline $\begin{array}{l}28 \\
37 \\
38 \\
36 \\
30 \\
30\end{array}$ & $\begin{array}{c}2 \\
1 \\
3 \\
10 \\
1 \frac{1}{2} \\
3 \frac{1}{2}\end{array}$ & $\begin{array}{l}28 \\
28 \\
40 \\
28 \\
28 \\
28\end{array}$ & $\begin{array}{c}5 \\
\text { None } \\
\text { None } \\
\text { None } \\
5 \\
2\end{array}$ & \\
\hline
\end{tabular}

An analysis of these 13 cases showed that the medulla of the shaft of long bones was affected in 19 instances, of which five were designated as highly probable, but not certain, involvement. The joints were involved in eight instances; in one of these the diagnosis might have been questioned. The films which were regarded as doubtful are not included. Of the 83 men who had had an attack of the bends, 10 had demonstrable changes in the bones. Of the 20 men who had not had an attack of bends, three showed demonstrabte changes in bones.

Towards the end of the investigation it was decided to examine men who had never had an attack of bends, it being thought possible they might show radiological changes; it is already known that medullary infarcts, when the joint is unaffected, are symptomless. Unfortunately, as many workers had left, there was at this time only a small group of 20 men who had worked for varying periods in compressed air without an attack of bends. Of these men, three showed some evidence of early infarction (see Table 3). No comparable population exists from whom control radiographs could be obtained; but the lesions recorded are such as had never occurred in routine hospital radiological work.

It was expected that a routine antero-posterior film would give all the information that was required to establish a diagnosis. This expectation was based on the frank abnormalities which have been reported in the literature. It was soon realized that lateral films were necessary to confirm the diagnosis in many cases, since minor variations in texture were discovered which might have been disregarded without the lateral projection.

Two results emerged: (1) Labourers who have worked for years in compressed air, and are still working without symptoms, may show evidence of aseptic necrosis in bones and joints; (2) Aseptic necrosis may be found in the absence of a history of bends for which treatment has been sought.

Pulmonary disease.-In two men (Cases 23 and 268) lung cysts were found by radiological examination (Fig. 3). In Case 23, there were two thin-walled cavities in the right lower zone of the lungs, measuring 1.5 in. in diameter, and not containing fluid. In Case 268, there was a single cyst, again in the right lower zone, $1.5 \mathrm{in}$. diameter; it contained a fluid level, indicating that it communicated with a bronchus and that the bronchus was partly occluded.

Although it must be supposed that these cysts were the cause of the sickness of the two men the evidence is only circumstantial. The mechanism by which they could do so is sufficiently clear. A partial occlusion of a bronchus could become complete at any time. Should this occur during decompression, the cyst must expand when the ambient pressure falls. This would lead, at least, to an abnormal gas exchange through the wall of the cyst, and possibly to rupture of the wall and discharge of gas into venous channels. A process of this sort would account for the peculiarities of Case 23, especially the fact that the rate of lowering of pressure during the recompression had to be far slower than is needed in conventional therapeutic decompression. This is intelligible if the problem were the elimination of free gas from a closed cystic space, rather than the elimination of dissolved gas from a tissue perfused by circulating blood. But the problem remains as to why, if the men have had the cysts for some time, they did not encounter trouble earlier; or, if the cysts were a result of damage to the lung, how such well defined cavities were produced, quite unlike the rents observed with lungs burst by raised intrapulmonary pressures.

These pressure effects in the lung are analogous 
to those which cause lesions in the middle ear when the Eustachian tube is blocked. The comparison suggests that complete blocking of minor bronchi in acute bronchitis or chronic bronchitis and emphysema might lead to decompression sickness and might even be a factor in the large variation of weekly bends incidence among labourers under constant working conditions. This would imply that patients with bronchitis and emphysema are not good risks for work in compressed air, and has prompted a further exploration of the radiological and physiological state of the respiratory tract in compressed air workers. A great advance in the prevention of decompression sicknesss, particularly of its major calamities, might be made if it were possible to radiograph the lungs of a patient in the recompression chamber during the attack.

Such cases present a therapeutic problem. In

Fig. 3a

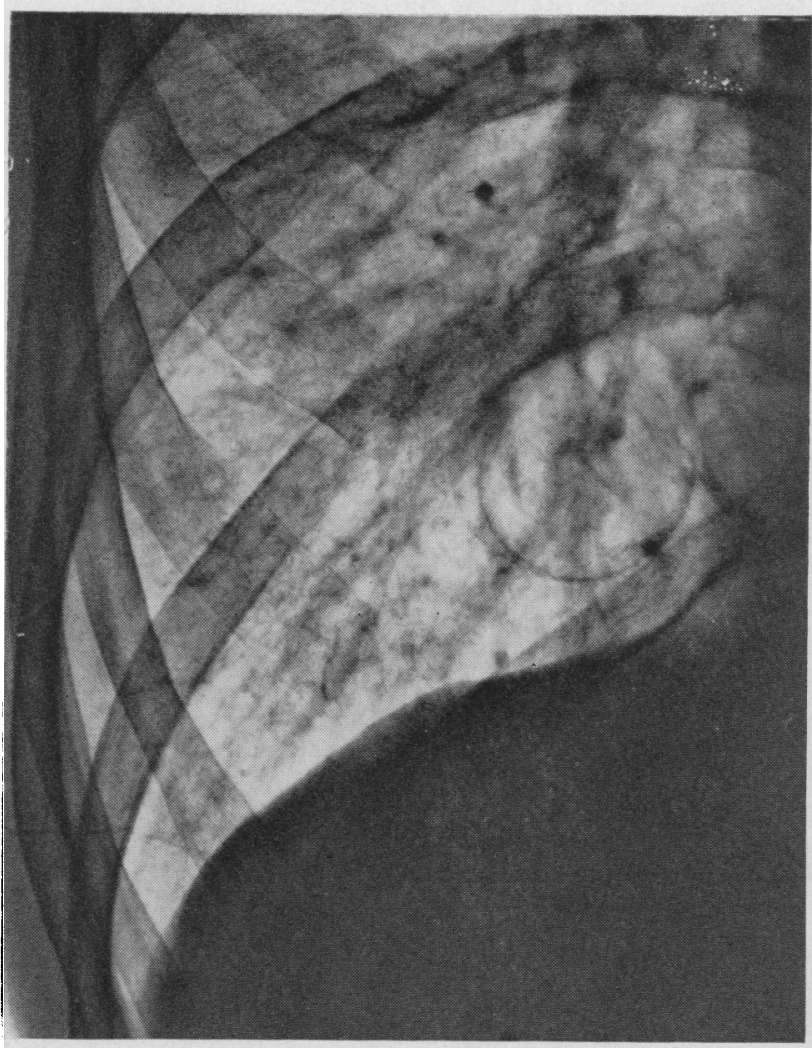

FIG. 3a.-Chest radiograph of Case 23. There are two cysts, one partly concealed by the right border of the heart: no fluid levels.

FIG. 3b.-Chest radiograph of Case 268. There is a cyst in right lower zone, containing a fluid level. the first place, the cyst cavities, being organized structures, cannot be made to disappear by high pressure or by prolonged treatment, as can a bubble. Secondly, it is usually supposed that bubble formation will not occur in the body until a large pressure change is experienced, but in the event of occlusion of a bronchus small pressure changes are likely to cause trouble. It is advisable that in any atypical or serious case of decompression sickness the possibility of a cyst or of occlusion of a bronchus be borne in mind and two general principles followed: extremely slow rates of therapeutic decompression should be used and, should symptoms recur, no attempt must be made to dissolve a bubble by recompressing the patient to high pressures; the pressure should be raised just sufficiently high to relieve the symptoms. When this has been achieved, the slow decompression can be resumed.

FIG. 3b

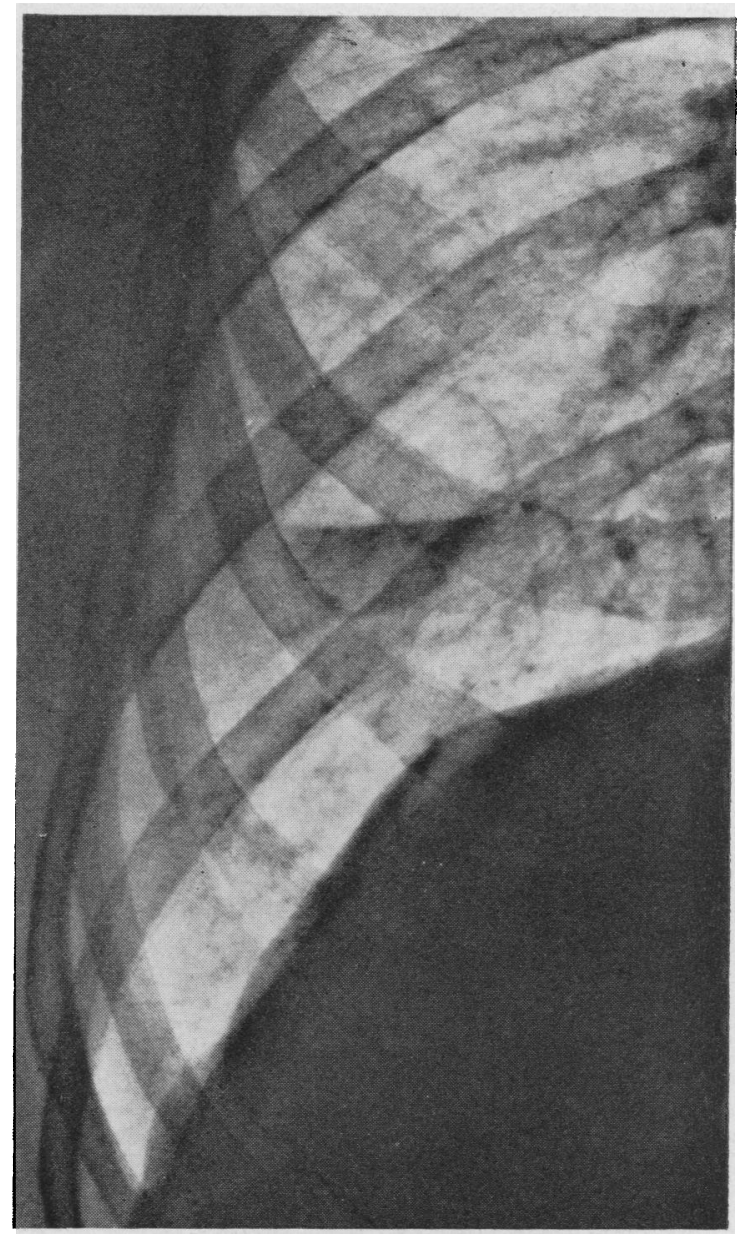


Statistical Analysis of Some Factors in Decompression Sickness

The number of cases of decompression sickness per 100 compressions will be called the "bends percentage". Table 4 summarizes the general bends rate over the whole period of the contract.

TABLE 4

INCIDENCE OF DECOMPRESSION SICKNESS

\begin{tabular}{|c|c|c|c|}
\hline Pressure (p.s.i.) & $\begin{array}{c}\text { Com- } \\
\text { pressions }\end{array}$ & Bends & $\%$ \\
\hline $\begin{array}{l}\text { Kent Side } \\
0-16 \text { All exposures } \\
16-18 \text { All exposures } \\
18-28 \text { Over } 4 \text { hours } \\
\text { Under } 4 \text { hours }\end{array}$ & $\begin{array}{r}530 \\
810 \\
55,900 \\
14,500\end{array}$ & $\begin{array}{r}\text { nil } \\
7 \\
576 \\
7\end{array}$ & $\begin{array}{l}\mathbf{0} \\
\mathbf{0 . 8 6} \\
\mathbf{1 . 0 3} \\
\mathbf{0 . 0 5}\end{array}$ \\
\hline $\begin{array}{l}\text { Essex Side } \\
0-16 \text { All exposures } \\
\text { 16-18 Over } 4 \text { hours } \\
\text { 18-21 Onder } 4 \text { hours } \\
\text { Over } 4 \text { hours } \\
\text { Under } 4 \text { hours }\end{array}$ & $\begin{array}{r}1,320 \\
17,500 \\
6,250 \\
16,800 \\
5,900\end{array}$ & $\begin{array}{c}\text { nil } \\
40 \\
\text { nil } \\
47 \\
\text { nil }\end{array}$ & $\begin{array}{l}0 \\
0 \cdot 23 \\
0 \\
0 \cdot 28 \\
0\end{array}$ \\
\hline $\begin{array}{l}\text { Caissons } \\
0-23 \text { up to } 12 \text { hours }\end{array}$ & $\begin{array}{c}2,400 \\
\text { (decanted) }\end{array}$ & 8 & 0.33 \\
\hline
\end{tabular}

For detailed analysis, the weekly bends incidence for the Kent side workings over the first 68 weeks of the contract was used. The incidence, plotted in Fig. 4a, varied considerably, from nil to $2.64 \%$, with a modal value of $0.5-1.0 \%$. It bore little direct relation to the pressure in the workings (Fig. 4b). The average bends percentage for the whole of this particular period, in this part of the workings where the tunnelling was hardest, was $0.98 \%$. This is a very creditable figure for the earlier part of a contract; but there are indications that it could be improved.

Variation in Susceptibility.-It was obvious that some men have more than their share of bends. The frequency with which men were attacked is shown in Table 5. This shows the way in which a relatively small group of men are responsible for quite a large proportion of the bends. As an example, if the 12 men with five or more bends were to be eliminated then the total number of bends would fall to 310 , and bring the average percentage over this 68 -week period from $0.98 \%$ to $0.77 \%$; if 43 men (about $4 \%$ of the working force) with three or more bends were eliminated, the bends incidence would be halved. A further point is that $20 \%$ of the total population of workmen had one or more attacks of the bends. Thus it is possible to judge the success of present procedures from contrasting points of view. For an individual worker the risk of an attack of bends at some time during his work in compressed air is quite high $(20 \%)$; but from the medical aspect the bends percentage, i.e., the number of bends per 100 compressions, is satisfactorily low $(1 \%)$.

Decompression Schedule (as described in the Work in Compressed Air Special Regulations, 1958).

Although the present decompression procedure affords considerable protection against bends we obtained evidence that it could be usefully revised, as regards two fundamental assumptions on which the calculations are based.

(1) In preparing the official decompression tables it has been assumed that 18 p.s.i. represents a safe threshold pressure below which negligible trouble would occur. This turned out to be untrue. In the first few weeks on the Kent side, while the pressure was rising from 10 p.s.i. to 18 p.s.i., the average weekly incidence rose steadily to over $0.8 \%$ and eight cases of bends occurred. This was sufficiently serious to call for a modified decompression schedule; to provide increased protection the slow phase of all decompressions was lengthened to 10 minutes per $\mathrm{lb}$. Men working at pressures from 16 to 18 p.s.i. were decompressed as though they had worked at 18 to 20 p.s.i. Even with this revised threshold pressure, 28 bends $(0 \cdot 2 \%)$ occurred in the Essex workings over a period of six months although the pressure never exceeded $17 \frac{1}{2}$ p.s.i. It appears, therefore, that even 16 p.s.i. is above the threshold pressure for absolute safety.

Another sign that the usual assumptions are inadequate appeared when the incidence on the Essex side was compared with that on the Kent side for a similar period; on the Kent side, the incidence was about four times greater, about $1.0 \%$. It is true that the pressure was much higher on the Kent side; but if the decompression tables were properly constructed, the protection should be equal at all working pressures.

(2) In calculating the present decompression routine, it has been assumed that four hours at some pressure is sufficient to ensure full saturation of the relevant body tissues to that pressure. In the decompression tables this assumption gives rise to decompression times which increase as duration of work increases until a four-hour exposure is reached.

TABLE 5

DISTRIBUTION OF BENDS OVER 68-WEEK PERIOD ON KENT SIDE

\begin{tabular}{|c|c|c|c|c|c|c|c|c|c|c|}
\hline $\begin{array}{l}\text { Number of bends per man } \\
\text { Number of men } \\
\text { Number of bends per group }\end{array}$ & $\begin{array}{r}0 \\
817 \\
0\end{array}$ & $\begin{array}{r}1 \\
118 \\
118\end{array}$ & $\begin{array}{r}2 \\
43 \\
86\end{array}$ & $\begin{array}{r}3 \\
18 \\
54\end{array}$ & $\begin{array}{r}4 \\
13 \\
52\end{array}$ & $\begin{array}{r}5 \\
5 \\
25\end{array}$ & $\begin{array}{l}6 \\
1 \\
6\end{array}$ & $\begin{array}{r}7 \\
4 \\
28\end{array}$ & $\begin{array}{l}8 \\
1 \\
8\end{array}$ & $\begin{array}{r}20 \\
1 \\
20\end{array}$ \\
\hline
\end{tabular}




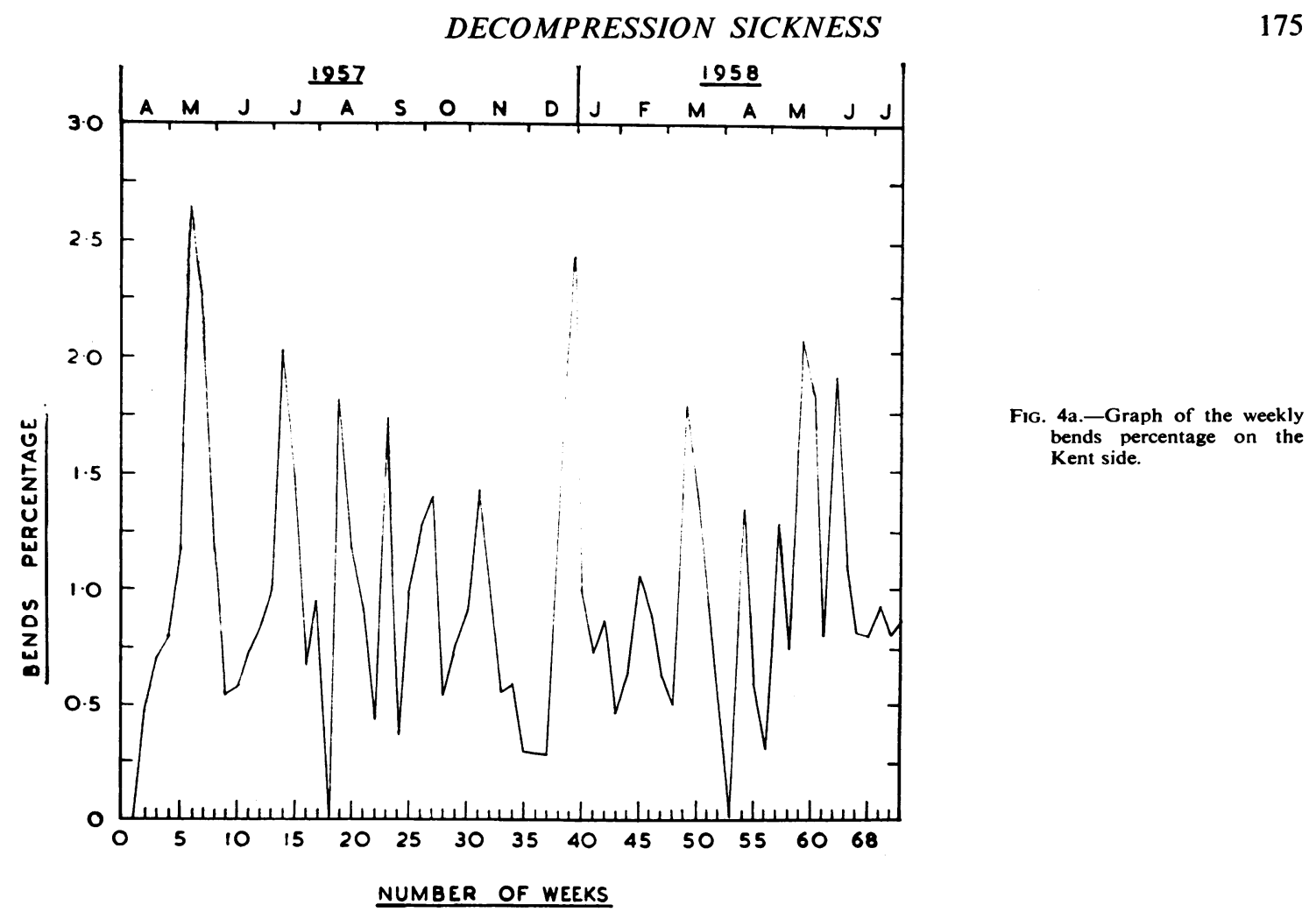

Fig. 4b.-Graph of the maximum weekly working pressure (p.s.i.).

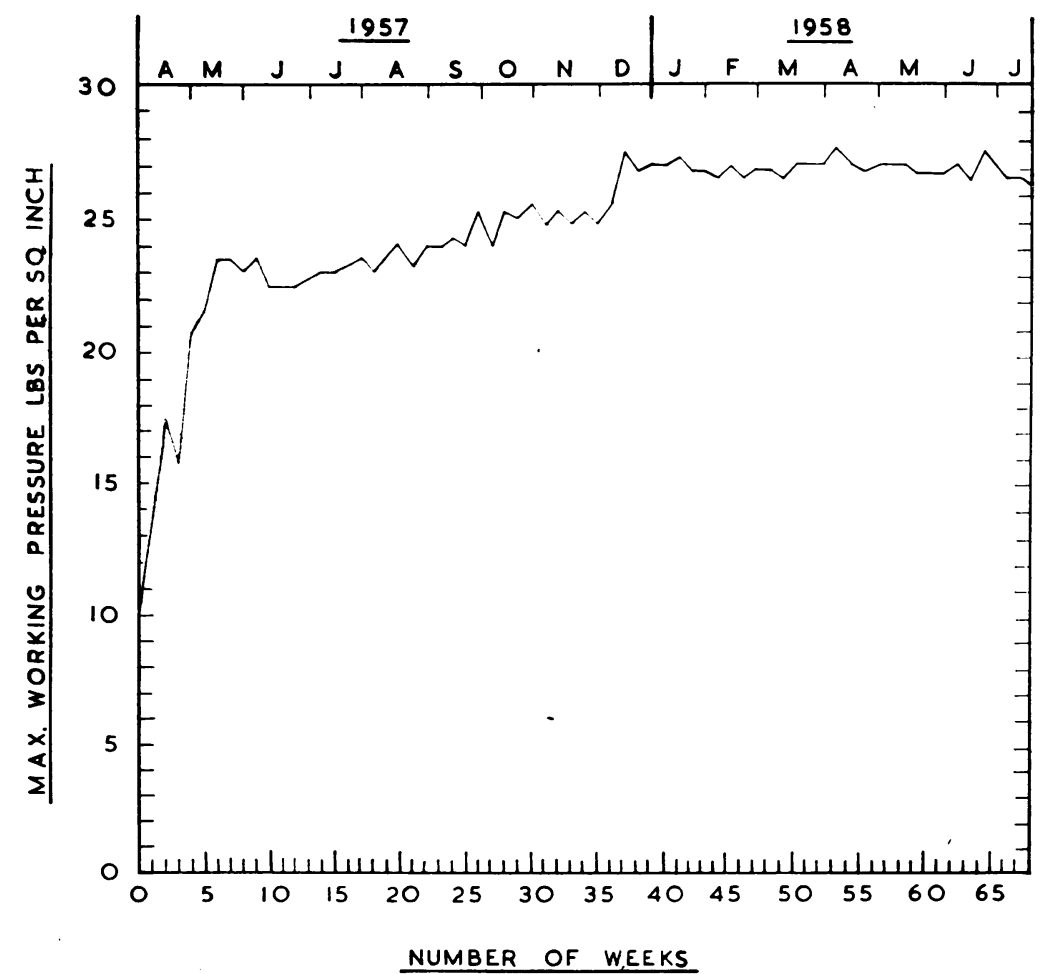


TABLE 6

VARIATION IN BENDS INCIDENCE WITH NATURE AND DURATION OF WORKING PERIOD

\begin{tabular}{|c|c|c|c|c|}
\hline & $\begin{array}{c}\text { Day Shift } \\
\text { (7 a.m.-3 p.m.) }\end{array}$ & $\begin{array}{c}\text { Back Shift } \\
\text { (3 p.m.-11 p.m.) }\end{array}$ & $\begin{array}{c}\text { Night Shift } \\
\text { (11 p.m.-7 a.m.) }\end{array}$ & Total \\
\hline $\begin{array}{l}\text { Number of compressions over four hours } \\
\text { Number of compressions under four hours } \\
\text { Bends percentage (over four hours) } \\
\text { Bends percentage (under four hours) } \\
\text { Overall percentage }\end{array}$ & $\begin{array}{l}12,943 \\
8.198 \\
1 \cdot 13 \\
0 \cdot 02 \\
0 \cdot 70\end{array}$ & $\begin{array}{l}7,905 \\
2,645 \\
1 \cdot 78 \\
0 \cdot 02 \\
1 \cdot 34\end{array}$ & $\begin{array}{c}8,174 \\
410 \\
1 \cdot 28 \\
0 \cdot 00 \\
1 \cdot 22\end{array}$ & $\begin{array}{l}29,022 \\
11,253 \\
1 \cdot 35 \\
0.03 \\
0.98\end{array}$ \\
\hline
\end{tabular}

All periods of work longer than four hours have, at present, the same decompression time. If this was a correct procedure, the risk of periods of work, four hours or less in duration, should be of the same order as periods of work greater than four hours duration. Table 6 shows an analysis of the experience over the 68-week period on the Kent side; it is quite clear $(p<0.001)$ that the risk is far greater with the longer exposure.

This table also brings out two other important points. The group of men exposed for four hours or more constitute the shift working population; it can be seen that they carry the greatest part of the bends risk. Further, there is a distinct tendency for the back shift to be the most hazardous $\left(\chi^{2}=37\right.$, d.f. $=2, p<0.001)$. This tendency persists even if the shift workers alone are considered $\left(\chi^{2}=16\right.$, d.f. $=2, p<0.001$ ).

Acclimatization.- The existence of a marked decline in bends incidence with the number of shifts worked was established in an earlier report (Paton and Walder, 1954). The present undertaking gave an opportunity to confirm and extend these findings. The ordinary shift workers proved to be an unsuitable group for this investigation; the reason was that the presence of alternative compressed air work in the district made it difficult to be certain that the new starters at Dartford were new starters at compressed air work. The employment of 22 steel erectors, who had never entered compressed air until they commenced work at Dartford, provided, however, a remarkable opportunity for examining this question. These men were all quite fit, and they were well used to the type of job which they performed in the tunnel. They were followed for a period of time of over one month, during which the pressure was relatively constant. The number of attacks of bends versus the number of shifts is shown in the histogram (Fig. 5). There is a large decline in the bends incidence with the passage of time; the data are well fitted $(r=0.97)$ by the regression line $\log _{10}$ (number of bends) $=1 \cdot 16-0.42$ (number of compressions) giving a half time of $7 \div 4$ compressions $(\mathrm{p}=0.05)$.

It was also found that working at low pressures for a few days does not appear to confer any measurable benefit on men subsequently introduced to higher pressures. This can be seen from Fig. 6 where a progressive rise of pressure caused an increase in the number of bends; but once the steady maximum level had been reached there was quite a marked fall in bends incidence very similar to that in Fig. 5, where no one had had previous experience of air work.

The confirmation of the existence of acclimatization to air work led naturally to the question of how long the acclimatization persisted when air work ceased. To answer this question the complete histories of a large number of men were scanned to see when an attack of bends occurred on returning to work after a period of absence. The week-ends gave a large number of two-day lapses in regular

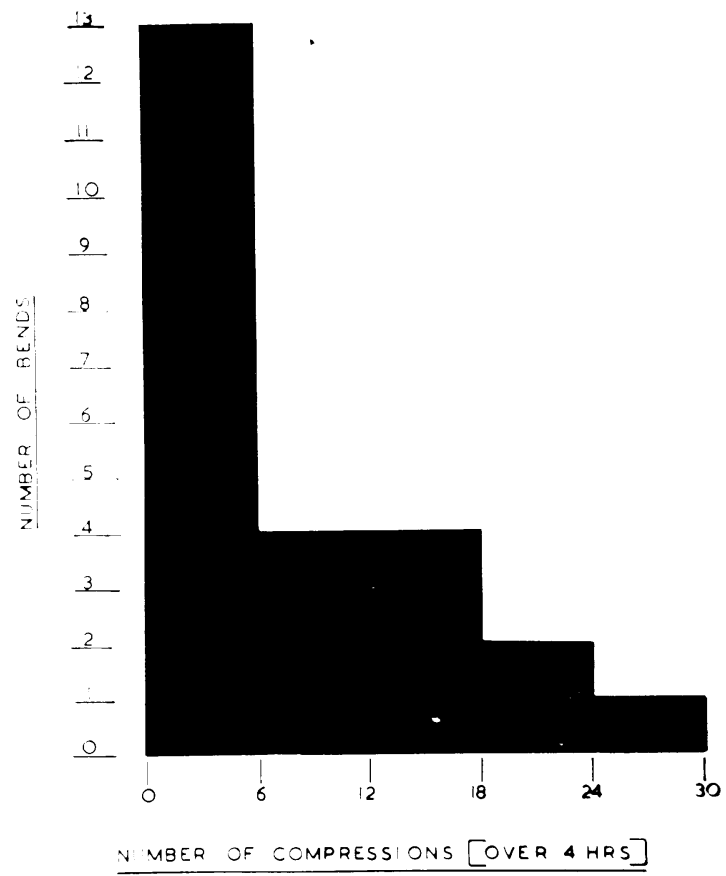

FIG. 5.-Graph of the number of bends occurring in a group of 22 steel erectors, for exposures over four hours, in relation to the number of compressions to which they had been exposed showing the development of acclimatization. 


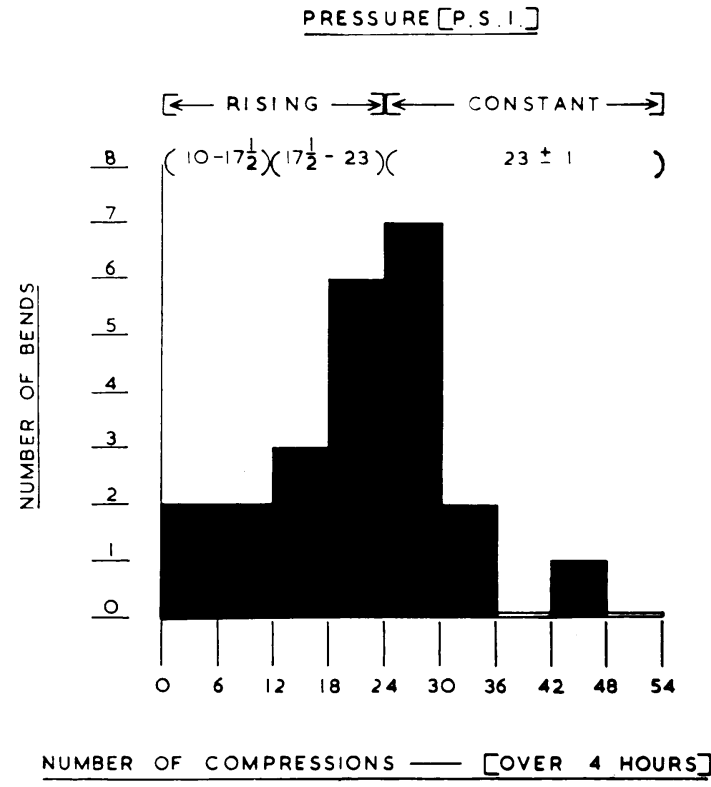

FIG. 6.-Graph of the number of bends occurring in relation to the number of compressions experienced, during a period when the pressure rose from 10 to 23 p.s.i., and then remained constant. Acclimatization did not begin until the pressure stabilized, showing that exposure to low pressures does not protect against exposure to higher pressures.

working, and holidays and strikes gave a large number of lapses of 10 days or over. Unfortunately, few figures accumulated for intermediate periods of time. Fig. 7 shows that whenever a man was away for a period exceeding 10 days then his chance of obtaining a bend on returning to work was very much greater than if he had been away for only two days. The two-day figure is represented by 14 bends and the over-10-day figure by 24 bends, the difference between them is highly significant. The intermediate points, whilst not contradicting the general trend do not permit any further quantitative statements to be made.

The existence of processes of acclimatization and "de-acclimatization" can now be seen to account for a great deal of the apparent randomness in the attacks of bends. The magnitude of the contribution of acclimatization and de-acclimatization may be judged by assuming that some procedure had been evolved to introduce new starters safely to compressed air work and to ensure that no bend occurred in the first three shifts after a period away from work of 10 days or more. In this eventuality the total number of bends over the 68 -weeks period would drop to 170 and the overall percentage from $0.98 \%$ to $0.42 \%$. The possibility of safely introducing men to higher pressures by first working them at lower pressures has already been shown to fail (Fig. 6). The time spent at the lower pressure appears to be quite irrelevant; thus there are nine cases of men who spent several months free from discomfort at 17 p.s.i. but when transferred to working at 27 p.s.i. had an attack of bends in the first few shifts at the new pressure. There remains the possibility of introducing men to compressed air working by gradually increasing the time worked at pressure. Since the half-time of the acclimatizing process is about seven days any such method would need to be quite prolonged in order to give useful protection. Unfortunately, there is no evidence from the present workings to indicate whether such a procedure would meet with success.

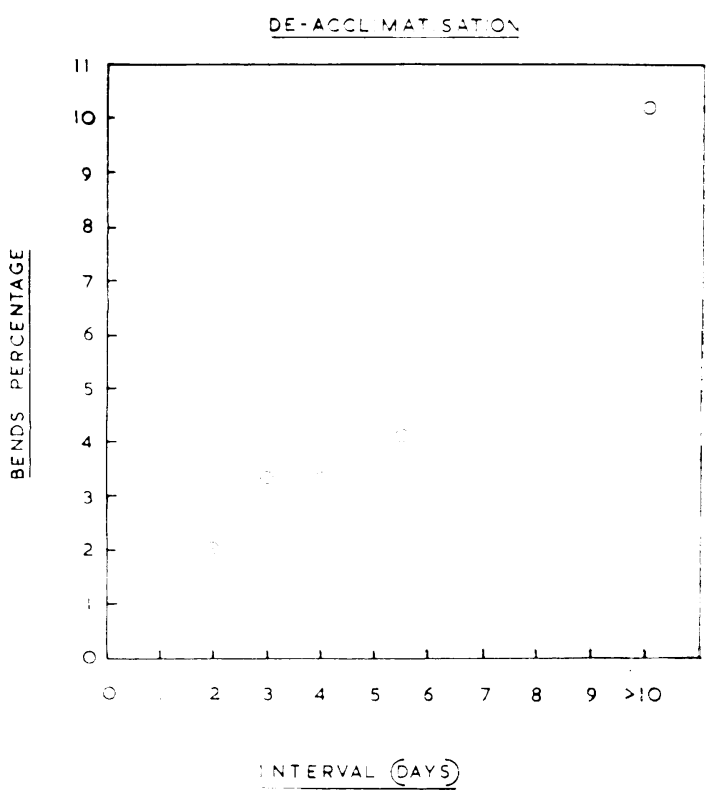

FIG. 7.-Graph of the increase in bends percentage against the duration of a period away from work under pressure.

Climatic Conditions.-During the construction of the Tyne Tunnel, Paton and Walder (1954) failed to find any connexion between the external climatic conditions prevailing and the bends rate. It was thought that the internal environment of the Dartford Tunnel should be investigated.

The most striking finding is the constancy of the internal environment of the tunnel. This appears to be quite independent of the external climatic conditions. Observations were made from September, 1957 to August, 1958 a period including 
great changes in the outside weather conditions. Yet the air temperature ranged only from 55 to $69^{\circ} \mathrm{F}$. and the relative humidity between $97 \%$ and $99 \%$. Considerable difficulty was experienced in measuring the wind velocity in the tunnel, because Katathermometer readings are inaccurate when made in compressed air, but the movement of titanium tetrachloride clouds and soap bubbles in the tunnel suggested that the wind velocity was of the order of $5 \mathrm{ft}$./min. At first sight it is surprising that men can do hard and prolonged physical work in an environment which is $97 \%$ saturated but calculation of the "corrected effective temperature" shows this to be well within the accepted limits of comfort. No relationship could be demonstrated between the internal environment of the tunnel and the bends rate.

\section{Methods of Treatment}

All cases were treated by recompression; the methods used were modified during the course of the contract, and were adapted to the nature of the case.

Type 1 Cases.-The majority of cases were compressed to $2-3 \mathrm{lb}$. above the working pressure and, after being free of symptoms for 10 minutes were decompressed in the usual way, as though for an exposure of more than four hours. If the patient was not free of symptoms after one hour at $3 \mathrm{lb}$. above working pressure, a higher pressure was used. On two occasions it was necessary to use $10 \mathrm{lb}$. above working pressure. The pressure at which fast decompression ceased and the slow phase commenced was, in every case, based on the highest pressure to which the man had been exposed in the previous 24 hours-either in the working chamber or medical lock. With this decompression time, however, a third of the cases required one or more further recompressions. For all cases after the first 50, the slow phase of the decompression was therefore lengthened from $9 \mathrm{~min} . / \mathrm{lb}$. to $15 \mathrm{~min}$./lb.; even so one in 10 required further recompression.

In 56 cases the pressure was raised, not as just described, to a few pounds above working pressure, but only to the pressure required to make the patient symptom-free; after 10 minutes at this pressure, routine decompression was carried out. The average "minimum effective pressure" required was $8 \mathrm{lb}$. below working pressure. The results were very satisfactory, only one case requiring a second recompression. The use of the minimum effective pressure was also found satisfactory when recompressing a second time; in these cases the man was kept at the requisite pressure for half an hour before decompressing.

About $25 \%$ of the men had a "residual soreness" at the end of treatment. There is a marked difference between this soreness and the pain of "bends" and the patient is always aware of the difference. Heat treatment (exposure to the radiations of an infra-red lamp) was found to be beneficial for this residual soreness as also was the use of tablets of aspirin or tab. codein co., B.P. In all cases the patient was considered to be free from the pain of "bends" at the end of treatment. If it was considered that, because of time spent in medical lock under treatment, the man had had insufficient sleep since his last shift, he was advised to miss a shift.

Type 2 Cases.-All cases were treated by immediate recompression. Initial recompression was always to working pressure, higher pressures being used when necessary to remove symptoms. The "effective pressure" was maintained for half an hour after all signs and symptoms had gone before decompression was commenced. The decompression was slow, and the patient was recompressed at once if signs or symptoms returned. For the first four cases the rate of decompression was $10 \mathrm{~min} . / \mathrm{lb}$. After the fourth case (23) a period of soaking of one to four hours at 12 or $15 \mathrm{lb}$. was added during the slow decompression. After the 19th case (306) a more prolonged course of treatment was used for all subsequent Type 2 cases. This treatment was as follows: The effective pressure was maintained for half an hour after all signs and symptoms had gone. The patient was then decompressed to 12 p.s.i. at $15 \mathrm{~min} . / \mathrm{lb}$. and "soaked" (i.e., maintained) at $12 \mathrm{lb}$. for four hours. Decompression was then continued at the rate of $1 \mathrm{lb}$. every half hour, "soaking" for one and a half hours at $8 \mathrm{lb}$., one hour at $4 \mathrm{lb}$., and one hour at $2 \mathrm{lb}$. Although this method may take 15-20 hours no additional recompressions have been necessary after its use. Any man who suffered a Type 2 attack of bends was either forbidden to go into compressed air again or strictly limited as to maximum permissible compression pressure and duration of exposure.

\section{Discussion}

In principle, decompression sickness should be a totally preventable disease. In fact, it is extremely difficult to eliminate. In assessing the incidence of sickness on this contract particular attention must be paid to two factors. The first is the number of compressions which take place at pressures where a risk exists. Often at the beginning of a working, only trivial pressures are used; yet recording each exposure as a "compression" may serve to lower enormously the overall bends rate. Without information as to the history of the pressure changes in the working, an overall bends rate can be almost 
meaningless (see, for instance, Kooperstein and Schuman, 1957); it is desirable to know the rate for pressures above 16 or 18 p.s.i.; and, on large contracts, the number of deaths or of cases of permanent disability, are important. The second factor is that of shift length. A common safeguard, used especially in the United States, is to shorten the time spent by each shift in compressed air as pressure rises. Thus a regime may be used which consists, for instance, of two spells of one and a half hours each in compressed air separated by an interval of three hours, which is very wasteful of manpower, but appears safe. The incidence of bends has ranged from about $0.05 \%$ to $1 \%$ with this type of regime (Norrie, 1934; Boulton, 1942; Levy, 1922; Keays, 1909; Kooperstein and Schuman, 1957). Deaths and permanent paraplegia have still, however, been recorded.

It may be that a procedure of this sort offers advantages. But the recent regulations agreed by the Ministry of Labour and the Institution of Civil Engineers in this country lowered the assumed "safe" working pressures from $22 \mathrm{lb}$. to $18 \mathrm{lb}$., and allowed shifts of eight hours or more; and exposures of this length have been used on this contract. A bends incidence, over the whole undertaking, of less than $2 \%$ has been regarded as satisfactory by the Institution of Civil Engineers. Reports of undertakings comparable with that discussed here are somewhat scanty. During the construction of a caisson (Lewis and Paton, 1957) an overall incidence of $4 \%$ was recorded. At the Tyne Tunnel (Paton and Walder, 1954) for pressures over 18 p.s.i. it was $0.87 \%$, with three cases of paraplegia. In the Dartford pilot tunnel built in 1937-8, the overall incidence was $0.9 \%$. It is satisfactory, therefore, that despite the large number of compressions $(119,000)$ at a pressure of over 16 p.s.i. and up to 28 p.s.i. there has been no fatal case, no permanent disability and an overall incidence of $0.55 \%$ (over 18 p.s.i. $0.93 \%$ ). The presence of a full-time doctor on the site (an unusual feature in such contracts) has ensured that all serious cases were properly treated. It may also have inspired a willingness by the men to return for treatment even in mild cases of bends, thus raising the recorded bends incidence.

Despite this satisfactory record, the occurrence of 650 cases of bends underlines the extent of the failure to abolish the disease. In planning a further attack on the problem of reducing the incidence of bends the first requirement is as full an account as possible of the natural history of the condition. For this reason alone, the confirmation that a process of acclimatization exists, and the further discovery that acclimatization is lost in a week or two if work under pressure ceases, is valuable; for without this knowledge it would be nearly impossible to reach a correct interpretation of the success or otherwise of particular decompression procedures. The cause of acclimatization and its loss remains obscure; it might be that the nuclei available for bubbleformation become used up (Harvey, 1951); or that the nerve endings responding to the painful stimulus produced in "bends" become adapted. The suggestion advanced by Paton and Walder (1954), that it followed an acclimatization to muscular exercise in general cannot be held, now that we know that work at a lower pressure does not acclimatize to work at a higher pressure. If acclimatization could be deliberately induced, without harm, and retained, this alone could lower the bends rate by a large factor; but no means of doing this can yet be indicated.

An obvious possibility for lessening the incidence of the disease is the elimination of susceptible subjects. Unfortunately at present there exists no means of identifying such men, save by seeing whether they get bends. Once employed, they are often willing to continue employment, with its high rates of pay, despite continuing occasional attacks. Our observations on lung pathology suggest that further investigations should be made into the possible relationship between the susceptibility to decompression sickness and lung lesions of a kind hitherto disregarded. This is being attempted.

A further scope for improvement is by modification of the decompression procedures. This has the troublesome feature that any improvement so far envisaged will lengthen the time the men are on the site, without increasing their useful working time. It is quite clear that two assumptions of current decompression theory, viz., that work in compressed air below 18 p.s.i. is absolutely safe, and that a man is fully saturated with nitrogen at four hours, are wrong. The question in this context simply becomes that of balancing an acceptable incidence of bends against a tolerable decompression time. There is lacking, however, any knowledge of what the incidence would be for an assumed safe pressure of 15 p.s.i., and full saturation time of eight hours; to know this would greatly assist the balancing of the issues. A further complication arises where bends follows some sort of injury; it may be that the site of an injury would give rise to pain on decompression at much lower pressures than normal.

Even if minor bends cannot be eliminated in the immediate future, the prospect seems more hopeful as regards the more important serious cases. The two cases we have described, who proved to have cysts in the lungs, exhibited a sequence of events which has occurred in serious cases elsewhere. Further, the character of these attacks and their 
severity are such that it is difficult to believe that the mechanism of their production is similar to the harmless limb pains of bends. A large potentially valvular airspace, however, could account for massive air embolism under changing pressure and we suspect that a good many other serious cases may have been due to a mechanism of this type. Routine chest radiographs should serve to eliminate men with such lung cysts from the population at risk (unless the cyst actually arises during a decompression).

The treatment of decompression sickness has also been studied. Two general approaches may be made to the problem; in the first (as in the U.S. Schedule for therapeutic recompression), one may choose high pressures in the hope of compressing any bubbles present and securing their rapid solution; the second approach is to keep the therapeutic pressure as low as possible, so as to minimize any contribution which absorption of nitrogen during the recompression itself may make to recurrence of the lesion. On the whole our experience has sup- ported the second approach; the need for subsequent recompression has been least when compression to the lowest effective pressure was used.

We are most indebted to Mr. J. Kell of Mott, Hay \& Anderson, and to Mr. R. H. Falkiner of Messrs. Edmund Nuttall, Sons \& Co. Ltd., and to Mr. E. Ll. Earp, O.B.E., contractor's agent, for their helpful cooperation; to the Air Ministry for the loan of the radiographic apparatus; and to Dr. R. C. Norton of the M.R.C. Head Office, for discussion and advice.

\section{REFERENCES}

Boulton, G. O. (1942). J. Instn Engrs Aust., 14, 1.

Harvey, E. N. (1951). In Decompression Sickness, pp. 90-164, ed. J. F. Fulton. [National Research Council, Washington, D.C.] Saunders, Philadelphia and London.

Keays, F. L. (1909). Compressed Air Illness. Cornell Univ., New York.

Kooperstein, S. I., and Schuman, B. J. (1957). Industr. Med. Surg., 26, 492 .

Levy, E. (1922). Compressed-Air Illness and its Engineering Importance. Rep. U.S. Bur. Min., Technical Paper 285.

Lewis, H. E., and Paton, W. D. M. (1957). Brit. J. industr. Med., 14, 5 .

Norrie C. M. (1934). Min. Proc. Instn civ. Engrs, 235, 281.

Paton, W. D. M., and Walder, D. N. (1954). Spec. Rep. Ser. Med. Res. Coun. (Lond.), No. 281. 